\title{
O que estudam os estudos de cultura visual?
}

Pablo Petit Passos Sérvio

Resumo: Este artigo busca respostas para a pergunta "o que estudam os estudos de cultura visual?". Busca demonstrar que a dificuldade em responder a esta interrogação feita com frequência por alunos que se interessam pelos trabalhos de autores vinculados à Cultura Visual é compreensível. Argumenta que isso ocorre porque, apesar das semelhanças aparentes entre estes trabalhos, eles trilham caminhos específicos. O texto propõe uma revisão bibliográfica que mapeia esse labirinto e auxilia os alunos a perceberem diferentes nuanças. Inicia questionando os conceitos de visão e visualidade e, em seguida, identifica dois importantes dissensos entre os autores deste campo. 0 primeiro, refere-se ao debate entre autores que focam exclusivamente experiências visuais mediadas por imagens ou artefatos visuais e aqueles que se posicionam em favor de um conceito de visualidade mais amplo do que "estudo de imagens". O segundo dissenso, refere-se à delimitação ou não de um foco histórico, ou seja: estudar toda e qualquer época ou apenas uma época específica? O artigo ressalta, ainda, que em meio a esses debates há uma variedade de usos da expressão "Cultura Visual" que precisa ser compreendida. Palavras-chave: cultura visual, visualidade, campo, objeto.

Hoje, já aprendi que é necessário fazer um percurso mais extenso e detalhado quando inicio discussões sobre Cultura Visual. Ser professor de uma disciplina chamada "Estudos de Cultura Visual" ajudou-me a ser mais cauteloso quando da introdução deste assunto, pois, nos diálogos com os alunos observei o quanto algumas de suas primeiras expectativas e dúvidas precisam ser consideradas. Ao longo das primeiras aulas já percebia que os alunos sentiam-se provocados. Entre eles já pipocavam uma série de perguntas e impressões. Qual a dimensão não cultural da visão? O que é biológico, instintivo ou programado na visão e o que é aprendido ao longo de nossa vida social? As imagens nos manipulam! O que seria uma cultura que não é visual? O que seria uma cultura auditiva ou tátil ou olfativa? Se não tivéssemos cultura, o que seria de nossa visão? A nossa cultura é visual? Ela é visual por causa das tecnologias que produzem muitas imagens! E se fossemos cegos, se fossemos animais sem olhos, o que aconteceria com a nossa cultura? Por um lado, essas perguntas e impressões parecem indicar o engajamento dos alunos com a disciplina. Contudo, isso não significa clareza em relação a algumas questões básicas. Quando perguntados sobre qual, então, é o objeto de estudo da Cultura Visual os alunos se entreolham não sabendo o que responder. Tantas são as questões suscitadas que eles se perdem no momento de responder de modo direto a perguntas aparentemente simples. Quero demostrar aqui que esta dificuldade tem como principal motivo a variedade de caminhos percorridos pelos autores que se vinculam a esta legenda. Considerando as dificuldades que tive quando me foi apresentado este campo, acredito que alguns alunos se perdem na ambivalência da expressão "Cultura Visual" Posso iniciar esta discussão sobre o objeto dos estudos da Cultura Visual trazendo à tona a distinção entre os conceitos de visualidade e visão, como proposta por Hal Foster. Para o autor (1988, p. IX),

Embora visão sugira a percepção visual como operação física, e visualidade a mesma percepção como fato social, as duas não se opõem como a 
natureza se opõe à cultura: a visão é também social e histórica, e a visualidade envolve corpo e psique. Todavia, não são idênticas: aqui, a diferença entre os termos assinala uma diferença no interior do visual entre os mecanismos da visão e suas técnicas históricas, entre o dado da visão e suas determinações discursivas - uma diferença, muitas diferenças, entre de que modo vemos, como somos capazes, autorizados ou levados a ver, e como vemos esse ver ou o não-visto dentro dele.

O que Foster chama de "visual" está dividido em dois planos. Esses planos não atuam de modo separado, mas tampouco são idênticos. 1) visão trata da percepção como operação física, trata de seus mecanismos e dados; e 2) visualidade trata da percepção como fato social, suas técnicas históricas e determinações discursivas. Enquanto a visão foca na parcela biológica da experiência visual, o corpo e a psique, a visualidade trata da parcela cultural da experiência visual, aquilo que é aprendido social e historicamente.

\section{Visão}

A maioria das pessoas concebe o olhar como sendo neutro, uma janela transparente para o mundo, para o real. No entanto, há muito tempo, a ciência empirista descreve em pormenores o fato de que não enxergamos com os olhos, mas, principalmente com o cérebro, e que este órgão tem extrema influência no modo como imaginamos e registramos as aparências do mundo. Sabe-se, por exemplo, que pelas características fisiológicas dos olhos, a percepção do ambiente ao nosso redor apreende as imagens de cabeça para baixo, em grande parte sem cores, e com dois pontos cegos. Se vemos da maneira como vemos, é porque o cérebro atua sobre as informações que nossos olhos conseguem codificar.

Sabe-se, também, que nem todas as informações enviadas pelos olhos ao cérebro são conscientemente processadas. Isso é o que demonstra a experiência desenvolvida pelos psicólogos Christopher Chabris e Daniel Simons (2011). A experiência propõe que você observe um vídeo ${ }^{1}$. As imagens do vídeo mostram três jovens vestidos de branco e outros três vestidos de preto. Os de branco tocam uma bola de basquete entre si, os de preto, passam outra bola de basquete entre si. Todos, no entanto, se misturam, pois, ocupam o mesmo espaço. Lança-se então um desafio para o observador, contar quantas vezes o grupo vestido de branco passa a bola de um para o outro. A maioria das pessoas acerta este número, entretanto a chave da experiência está no que elas não perceberam.

De tanto concentrar-se nas pessoas de branco, em média, cinquenta por cento dos espectadores não percebe que durante o vídeo um homem vestido de gorila vem devagar ao centro da tela, bate as mãos no peito e, então, sai do enquadramento com a mesma calma. A experiência demonstra que o cérebro não tem a capacidade de processar conscientemente todas as informações visuais que os olhos captam e, diante disso, dedicase apenas àquelas informações que presume nos interessarem mais. Esse fenômeno é

\footnotetext{
${ }^{1}$ Você pode assistir a este vídeo através do link: http://youtu.be/vJG698U2Mvo
} 
conhecido como percepção seletiva, processo através do qual enxergamos conscientemente apenas aquilo a que devotamos atenção.

Recentemente descobriu-se, também, (LAMEIRA; GAWRYSZEWSKI; PEREIRA, 2006) regiões do cérebro em que se encontram um tipo especial de neurônios chamados de Neurônios Espelho. Esta região é especial porque, ao registrar visualmente a execução de uma ação, pode processá-la exatamente da mesma forma, como se o próprio observador estivesse fazendo a ação. Em outras palavras, ao ver alguém fazer algo (incluindo a expressão de sentimento), os neurônios do observador, além de registrar a visão da ação, também comportam-se como se estivessem executando a ação. Seriam estes neurônios a base biológica que possibilita que nos engajemos emocionalmente, por exemplo, às ações que performam os personagens de um filme e que executam os atletas de nossos esportes favoritos. Estes neurônios seriam a base biológica para a empatia e suspeita-se que a ausência deles no cérebro esteja relacionada à uma possível explicação para o autismo.

Estas pesquisas dedicam-se ao que Hal Foster chama de visão, ou seja, à dimensão fisiológica do olhar. Campos de estudo como a Psicologia da Percepção ou a Neurociência especializaram-se em descrever e estudar as bases biológicas da experiência visual.

Mas esta não é a preocupação e muito menos o ponto de convergência dos estudos da Cultura Visual ${ }^{2}$. Para compreendermos os enfoques da Cultura Visual devemos nos dedicar à visualidade, ou seja, à dimensão cultural do olhar, dimensão histórica e contextual. Com o foco nesta dimensão este campo poderá repensar os exemplos dados acima.

\section{Visualidade}

É à visualidade que a cultura visual se dedica. Como explica Paulo Knauss (2006, p. 107), "trata-se de abandonar a centralidade da categoria de visão e admitir a especificidade cultural da visualidade para caracterizar transformações históricas da visualidade e contextualizar a visão". Se nossa experiência visual não pode ser identificada como uma janela transparente para o real, em função das diferentes práticas e variantes culturais, logo não pode ser compreendida como uma experiência natural/ universal no sentido de que seja igual para todos independente do contexto histórico.

\footnotetext{
${ }^{2}$ Definitivamente não é a principal preocupação. Ainda assim, autores como James Elkins (2003), em sua lista denominada Dez maneiras de fazer os Estudos Visuais mais difíceis (ten ways to make visual studies more difficult) defendem que os estudantes de Cultura Visual deveriam aproveitar mais os achados da psicologia cognitiva, da óptica fisiológica, da neurologia da visão e da neurobiologia da visão. Para Elkins, aproximar-se de tais estudos, ao contrário do que alguns autores querem indicar, "não compromete as reinvindicações do construcionismo social" (2003, p. 87). Apesar de não pontuar os campos de estudo das ciências naturais que a Cultura Visual deve apropriar-se, assim como o faz Elkins, Mitchell também defende que uma versão dialética da Cultura Visual presume que "a própria noção da visão como atividade cultural necessariamente encerre uma investigação de suas dimensões não-culturais", nesse sentido deve considerar a "naturalidade da visão e das imagens visuais como um problema a ser explorado, antes de encará-las como um preconceito obscuro a ser superado" (2002, p.171).
} 
Para Martin Jay (2002), o congresso a partir do qual Hal Foster organizou o livro Vision and Visuality (1988) representa um impulso decisivo para a organização desse campo de estudo. Jay ressalta que "somente na ocasião do congresso da 'Dia Art Foundation' uma massa crítica começou a unir-se em torno da questão da determinação cultural da experiência visual em sentido amplo" (p. 267-268) 3. W.J.T. Mitchell (2002, p. 170-171), também defende que a Cultura Visual surge quando compreendemos que experimentamos o visual por meio da cultura, por meio de construções simbólicas, como "um sistema de códigos que interpõem um véu ideológico entre nós e o mundo real". Assim, os processos que constroem as visualidades que se manifestam como práticas da cultura visual resultam de aprendizados durante o curso de nossa vida social. Portanto, pensar o contexto histórico e local no qual estamos inseridos como parte de um universo cultural torna-se indispensável para qualquer análise que almeje aprofundar-se na compreensão de experiências visuais.

A cultura influencia nossa experiência visual de modo muitas vezes aparentemente insuspeito. Observamos anteriormente, quando analisamos aspectos da dimensão biológica do olhar (visão), a existência do fenômeno da percepção seletiva. Dissemos que o cérebro, mesmo em estado de consciência, processa apenas uma pequena parcela das informações enviadas pelos olhos, devido a limitações biológicas. O que não destacamos é que a dimensão cultural, em grande medida, nos predispõe a focar nossas atenções para algumas coisas, eventos ou pessoas e não para outras. A percepção seletiva é construída de maneira tácita, a partir de rotinas, de preferências e de práticas de olhar que se estruturam e ganham organicidade interna sem que nos demos conta. Ela se desenvolve de maneira inconsciente, influenciada por práticas culturais, por estímulos externos e/ou internos sobre os quais não temos controle. Um exemplo é o caso dos garis, descritos por Fernando Braga da Costa (2004) como "homens invisíveis", homens e mulheres que quando vestem o uniforme relatam que não são mais vistos. Este é, também, um exemplo de como as roupas tornaram-se fundamentais para a nossa sociabilização, podendo nos destacar ou, até mesmo, apagar. Para pensar o caso dos Garis seria, portanto, necessário não se satisfazer simplesmente com a ideia de que a percepção é seletiva. É preciso compreender porque em tal contexto certas roupas levam certos indivíduos à invisibilidade.

Neste mesmo sentido, no artigo After Cultural Theory: The Power of Images, the Lure of Immediacy, Janet Wollf (2012) discute, entre outras coisas, as pesquisas sobre neurônios espelho sobre o ponto de vista da Cultura Visual, ou seja, questionando as limitações deste tipo de estudo e defendendo a necessidade de uma teoria crítica sociológica, interpretativa,

\footnotetext{
${ }^{3}$ Embora Martin Jay (2002) destaque este evento como um impulso decisivo para o campo, ele também aponta outras iniciativas ou antecipações que incluem trabalhos de W.J.T. Mitchell, Richard Rorty, John Berger, Erwin Panofsky e Michael Baxandall.
} 
hermenêutica, como base para pensar as experiências visuais. Segundo a autora, o fato de que possuímos esta base biológica não explica, pensando casos específicos, porque nos identificamos e temos pré-disposição para ter empatia com certas pessoas, e em certas ocasiões, e não com outras. É neste sentido que podemos pensar o debate citado por Douglas Kellner (2001) sobre um estudo de recepção feito em uma sala de cinema em que se projetava o filme Duro de Matar (Die hard, 1988). Neste estudo se identificou que a maioria dos espectadores não identificavam-se com os policiais, mas, com os bandidos, a ponto de sentirem prazer nas cenas em que a polícia era humilhada.

Sendo assim, toda e qualquer conhecimento sobre uma característica que se suponha biológica do olhar será sempre insuficiente para ajudar-nos a compreender casos específicos se não somarmos a tais conhecimentos influências históricas que caracterizam a cultura na qual se localiza o fenômeno que desejemos entender. Martin Jay (1994, p.89) revisa a implicação da cultura no olhar da seguinte forma:

Ao contrário dos outros sentidos, olfato, tato ou paladar, parece haver uma relação próxima, ou complicada, entre visão e linguagem, que desenvolvem-se aproximadamente no mesmo momento de maturação. Como Robert Rivlin e Karen Gravelle notam, "a capacidade de visualizar algo internamente está intimamente ligada à capacidade de descrevê-lo verbalmente". Descrições verbais e escritas criam imagens mentais muito específicas... A ligação entre a visão, memória visual e verbalização pode ser bastante surpreendente. (...) As implicações deste último ponto são muito importantes para o problema mencionado anteriormente: a permeabilidade da fronteira entre o componente "natural" e o "cultural" no que chamamos de visão. (...) Como resultado, a universalidade da experiência visual não pode ser automaticamente assumida, se esta experiência é em parte mediada linguisticamente. A própria ciência natural, portanto, sugere a possibilidade de variáveis culturais, pelo menos em algum grau. Implica, em outras palavras, o entrelaçamento inevitável da visão e do que tem sido chamado de "visualidade" - as manifestações históricas distintas da experiência visual em todos seus possíveis modos. (grifo meu) É por isso que Foster (1988) sublinha que visão e visualidade não se opõem apesar de não serem idênticas.

Qual é, então, o objeto de estudo deste campo? Podemos concluir, por fim, que a Cultura Visual estuda a visualidade ${ }^{4}$, ou seja, a dimensão cultural do olhar? Esta seria uma resposta correta, contudo, pode vir a soar demasiadamente ampla quando nos aproximamos de estudos concretos de certos autores. Ocorre que não há um único foco dentre os autores da Cultura Visual, alguns optam por caminhos bastante específicos. Logo, é necessário conhecer algumas propostas e abordagens se quisermos chegar às nossas próprias conclusões.

\section{$1^{\circ}$ Dissenso: Estuda apenas as experiências visuais mediadas por imagens?}

Falar que a cultura visual estuda a dimensão cultural da experiência visual pode não ser a forma mais adequada de explicar ou compreender as principais linhas de pensamento existentes no campo, pois, alguns autores se dedicam a uma experiência visual específica,

\footnotetext{
${ }^{4}$ Nicolas Mirzoeff traça uma genealogia do termo visualidade no artigo On Visuality, de 2006.
} 
aquelas mediadas por imagens. É o caso de John A. Walker e Sarah Chaplin (2002, p. 42). Eles afirmam que estudantes de Cultura Visual "não estão interessados, principalmente, na forma como as pessoas veem o mundo, mas na forma como as pessoas veem as imagens estáticas ou em movimento e outros artefatos que foram feitos, em parte ou totalmente, para ser vistos" ${ }^{\prime \prime}$.

Discutir as imagens que nos cercam é algo fundamental para a Cultura Visual. Em parte este tem sido o meu esforço. Ao longo dos últimos anos tenho me dedicado especificamente às imagens de publicidade/propaganda e o modo como elas, por vezes, estão intrinsecamente relacionadas à legitimação de uma série de padrões culturais - como, por exemplo, um tipo de hedonismo e de individualismo. Outros autores, no entanto, já demonstraram que são muitas as possibilidades de discutir as imagens. Já se discutiu sitcom e cinema de fiç̧ão científica (MIRZOEFF, 2008; 2000), grafite (CAMPOS, 2007), fotografias e a consolidação do movimento dos direitos humanos (SLIWINSKI, 2006), a transmissão de guerras através da TV e imagens de violência em geral (JAY, 2003; MITCHELL, 2011) a relação das imagens com a construção da memória sobre temas como a epidemia de AIDS (STURKEN, 1997) e tantos outros temas.

Para os autores que trabalham com Cultura Visual as imagens importam, pois, em vez de simplesmente refletirem a realidade ou um contexto (como costuma entender o senso comum), nossa relação com as imagens afeta/constrói percepções sobre o mundo e sobre nós mesmos, influenciando nossas ações. Portanto, as imagens estão intrinsecamente conectadas à política e à relações de poder. Contudo, isso não significa que os autores focam seus esforços exclusivamente na interpretação de imagens ou no papel delas na dinâmica social.

A centralidade que o autor deve dar à experiência visual mediada por imagens é uma das principais divergências entre aqueles que investigam e trabalham com Cultura Visual. Para alguns, este seria o foco, enquanto para outros, esta seria apenas parte da preocupação. Me alinho ao segundo grupo.

A meu ver se aceitarmos que a Cultura Visual ganha impulso e, de certa forma começa a se organizar como campo de estudo a partir do momento em que tomamos consciência da força das determinações culturais da experiência visual, ou seja, o que chamamos visualidade, parece incongruente concordar com um foco exclusivo nas imagens. Associando-me a posição de Mitchell (2002) nego este foco que, de certa forma, reduz a

\footnotetext{
${ }^{5}$ É importante observar que na página que antecede esta citação do livro de John A. Walker e Sarah Chaplin (2002) podemos encontrar a definição do termo visualidade. Ela coincide com a definição que está sendo utilizada neste trabalho: visualidade - em oposição à visão, um processo físico/fisiológico - faz referência a um processo social, quando a experiência retiniana é articulada à cultura. Contudo, o foco nas imagens ou artefatos visuais ganha espaço a ponto de pesquisadores usarem a palavra visualidade para indicar não mais a dimensão cultural da experiência visual, como o fazem Walker e Chaplin, mas, para indicar essas próprias imagens e artefatos visuais. Para mim, usar a palavra visualidade para indicar objetos tira desta palavra sua potencialidade.
} 
Cultura Visual apenas a algo como "estudos de imagens". Opondo-se a essa ideia, Mitchell explica que "mesmo algo tão vasto como é a imagem, não exaure o campo da visualidade" (p.178). Ou seja, o estudo da imagem é uma parte importante, mas, apenas uma parte dos Estudos de Cultura Visual. Mitchell (idem) detalha esta questão através da análise do caso de sociedades muçulmanas em que a produção de imagens é proibida.

\begin{abstract}
Sociedades que baniram a imagem (como o Taliban) ainda têm uma cultura visual rigorosamente policiada na qual as práticas corriqueiras da exposição humana (especialmente de corpos femininos) são objeto de regulamentação. Poderemos ir ainda mais longe ao dizer que a cultura visual emerge em seu relevo mais evidente quando o segundo mandamento, que bane a produção e exposição de imagens sagradas, é observado de modo mais literal, quando o ver é proibido e a invisibilidade é ordenada. (p.178179)
\end{abstract}

Em outras palavras, o autor advoga em favor da definição não só das imagens, mas da experiência visual como um todo como objeto de estudo da Cultura Visual. Para Mitchell (2002), discutir Cultura Visual inclui, necessariamente, portanto, além de imagens, tudo aquilo que vemos, olhamos, mostramos e exibimos, assim como o que escondemos, dissimulamos e nos recusamos a ver. Stuart Hall e Jessica Evans (1999), da mesma forma, afirmam que o campo da Cultura Visual também inclui as práticas cotidianas de olhar e exposição. Ulpiano Meneses (2005) acompanha Jonathan Crary $(2012)^{6}$, ao concordar que ir além das imagens é importante porque uma história da visão inclui muito mais do que simples alterações nas práticas de representação. Se pensarmos as experiências visuais por meio das noções de poder e dos tipos de controle que as sociedades exercem ao lidar com o visível, como sustenta Meneses (idem), perceberemos que as culturas estão repletas de prescrições sobre o que se deve obrigatoriamente ver, assim como o que não se deve ver (caso em que se converte em tabu), assim como prescrições sobre quem pode ou quem não pode ver, e quem deve ou não deve ser visto.

Para melhor compreender este ponto você pode fazer-se algumas perguntas. Por exemplo: de acordo com os valores de sua cultura que coisas, ações/eventos ou pessoas não podem ou não devem ser exibidas ou vistas por todos? Existem costumes nos quais em algum evento específico certas pessoas tem direito de ver certas coisas e outras não?

Certa vez, em sala de aula, fiz estas perguntas aos alunos. Lembro-me que um aluno respondeu-me meio envergonhado que o homem brasileiro tinha o hábito de, após cruzar com uma mulher em espaços públicos, virar-se descaradamente para olhar sua bunda. Muitos na sala riram, esperando que eu dissesse que aquela não era uma resposta pertinente. No entanto, aquele exemplo acabou por provocar um interessante debate sobre

\footnotetext{
${ }^{6}$ Crary (2012) propõe, inclusive, que a história da arte feita no século XIX não conseguia compreender a arte daquele momento, pois focava exclusivamente em obras esquecendo-se de avaliar as mudanças no observador, ou seja, na história da construção social da visão.
} 
como a dimensão cultural pode marcar a experiência visual no que se refere à definição de quem deve ver (observador) e quem deve ser visto (observado).

Para tanto, estudamos o exemplo trabalhado por John Berger (1999) no livro Modos de Ver. De acordo com Berger, homens e mulheres têm papéis distintos em nossa cultura. Segundo este autor, "os homens olham para as mulheres. As mulheres veem-se a serem vistas. Isto determina não só a maioria das relações entre homens e mulheres como também as relações das mulheres consigo próprias" (p. 51). Berger alerta para o profundo efeito desta dimensão cultural sobre a constituição da subjetividade da mulher. Ele diz: "o vigilante da mulher dentro de si própria é masculina: a vigiada, feminina. Assim, a mulher transforma-se a si própria em objeto - e muito especialmente num objeto visual: uma visão" (idem).

Esta lógica de quem vê e quem deve dar-se a ver pode ser observada em algumas imagens, embora, obviamente não dependa da existência de imagens. Na obra de Tintoretto, Susana e os velhos (figura 1), Bergman (1999) identifica um exemplo paradigmático do que está a dizer. Nessa imagem, a mulher, que está totalmente nua, observa-se no espelho ao mesmo tempo em que é espiada por homens escondidos. Esta lógica que faz da mulher objeto do olhar de desejo (gaze) masculino pode ser observada também em várias fotografias publicitárias, a exemplo dos anúncios de Dolce \& Gabbana e Melissa (figuras 2 e 3)

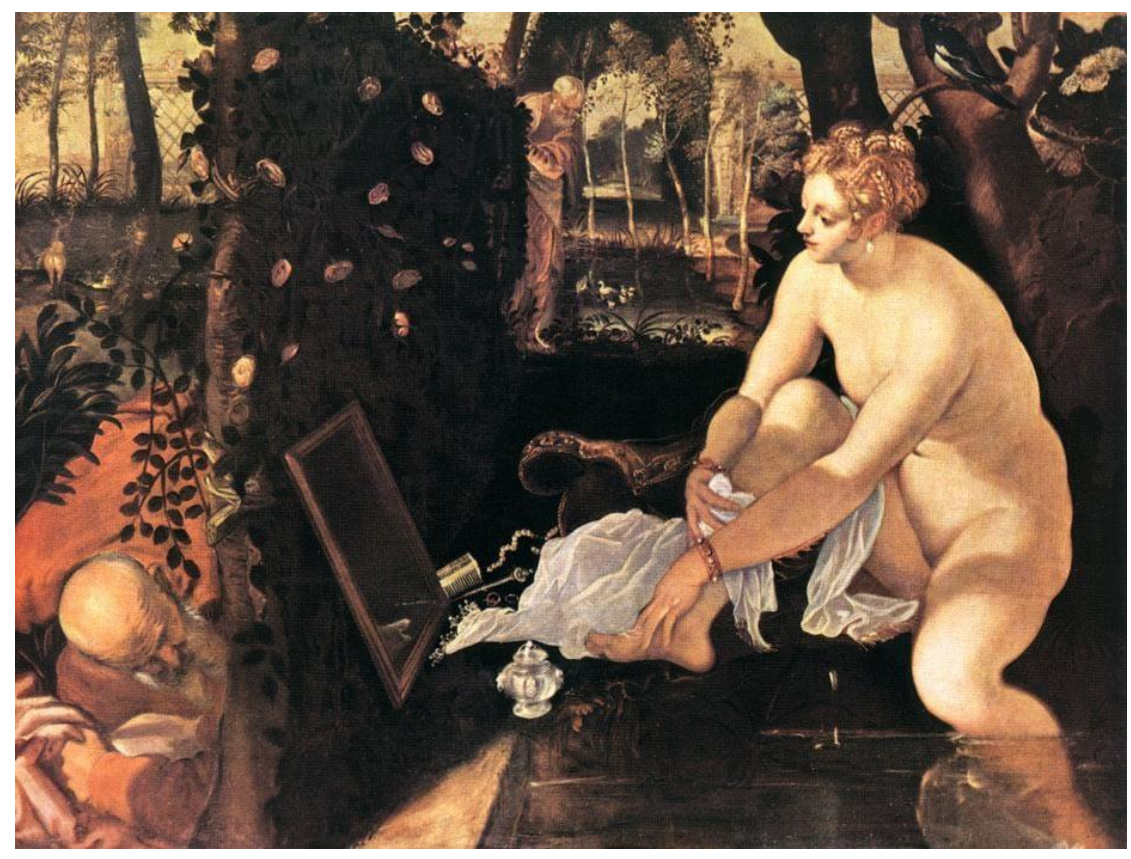

Figura 1 - "Susana e os velhos". Jacopo Tintoretto, 1560 


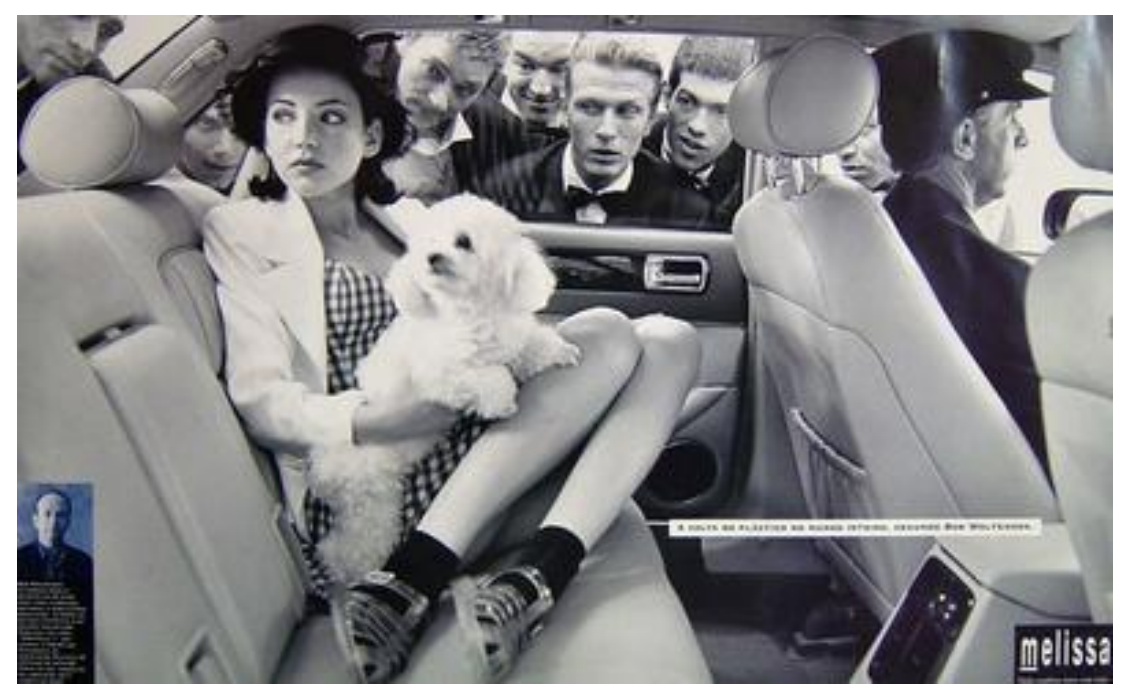

Figura 2 - Anúncio da marca Melissa

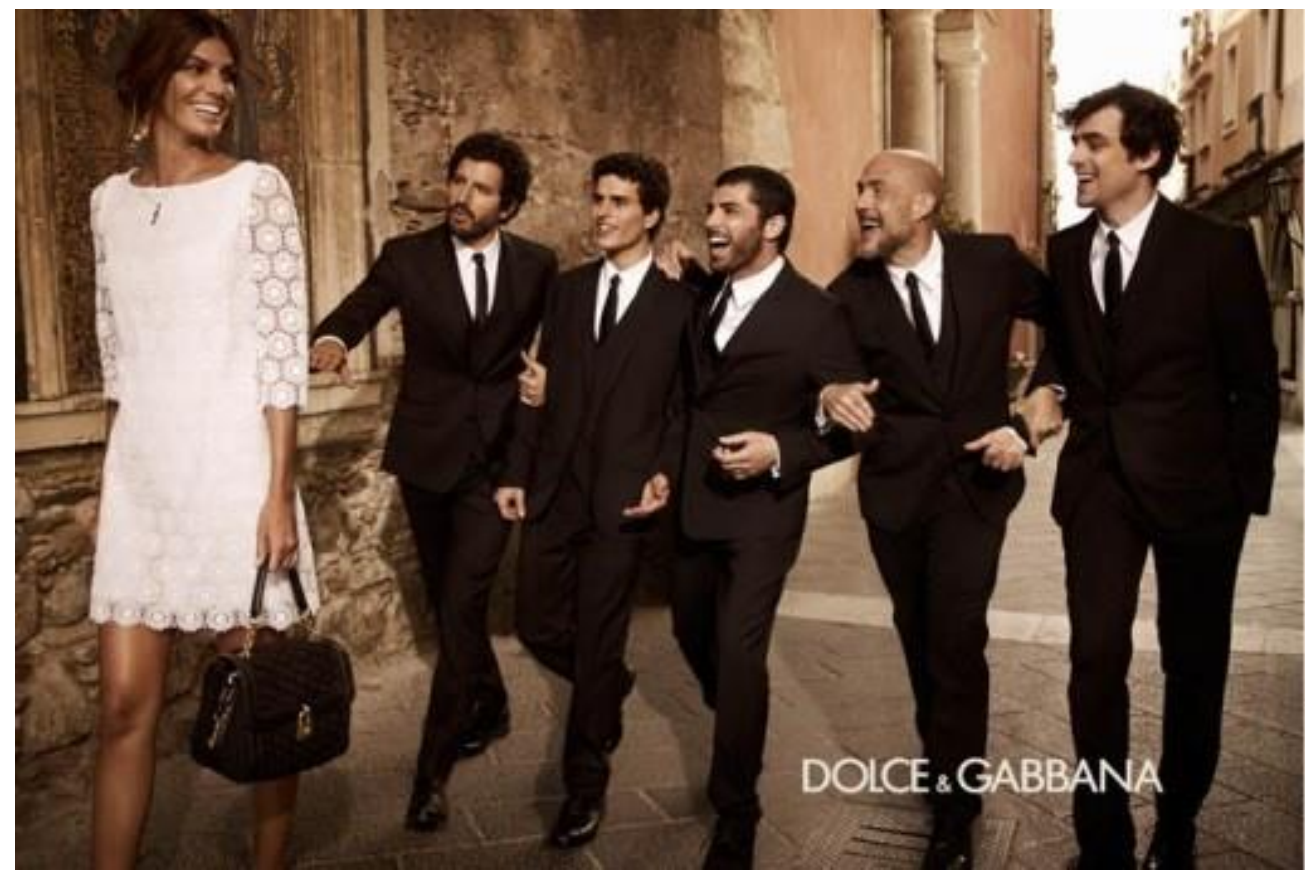

Figura 3 - Anúncio da marca Dolce \& Gabanna

Segundo Bergman, esses distintos papeis de homens e mulheres refletem-se nos distintos modos como os gêneros são representados". Enquanto "os homens agem, as mulheres aparecem", ele diz. Entretanto, fica óbvio que sua análise fala muito mais do que de imagens, fala da experiência visual em sentido amplo. Discute sobre como homens e

\footnotetext{
7 Nesse sentido é importante conhecer as obras das artistas feministas do grupo Guerrila Girls (http://www.querrillagirls.com/). Também é bastante frutífero conhecer o trabalho da artista francesa Orlan (http://www.orlan.eu/) e da espanhola Yolanda Dominguez (http://www.yolandadominguez.com).
} 
mulheres são levados a ter experiências visuais distintas, experiências que hoje existem em paralelo a tais imagens.

\section{$2^{\circ}$ Dissenso: Estuda uma cultura específica? Afinal, que cultura é essa cultura que é visual?}

Argumentei até aqui que o objeto de estudo deste campo denominado Cultura Visual é a dimensão cultural da experiência visual e que ao tratar de experiência visual incluem-se as imagens, mas, que as imagens são apenas parte do objeto de estudo deste campo. Como ressalva, destaco que nem todos os autores ligados à Cultura Visual adotam ou concordam com esta posição já que alguns dedicam-se exclusivamente às experiências mediadas por imagens.

Neste tópico espero discutir um segundo ponto de discordância entre os autores da Cultura Visual. Enquanto o tópico anterior dá a entender que os estudos feitos no campo da Cultura Visual dedicam-se a toda e qualquer experiência visual, seja qual for seu contexto cultural, é importante ter consciência de que alguns autores (nem todos) defendem que a Cultura Visual é um campo de estudos devotado a estudar um contexto cultural específico. Neste sentido, a posição de Nicolas Mirzoeff (1999, p.6) é particularmente importante e merecer ser analisada. Considerando que é um dos autores mais reconhecidos deste campo de estudo e com maior difusão, é necessário discuti-lo.

Para Mirzoeff, Cultura Visual, antes de ser uma disciplina, é "uma tática com a qual estudar a genealogia, a definição e função do cotidiano pós-moderno do ponto de vista dos consumidores, ao invés dos produtores" (p. 3). Analisando esta afirmação podemos observar dois pontos em que o autor delimita a preocupação do campo da Cultura Visual: A) Seu esforço para pensar um contexto cultural específico, que ele mesmo define como pós-moderno e B) Sua preocupação especifica com práticas que identifica como de consumo. Neste tópico nos interessa pensar o primeiro ponto.

A preferência de Mirzoeff pela cultura pós-moderna justifica-se pelo fato de que para ele esta seria eminentemente visual. Ou seja, viveríamos em uma cultura que é visual. Mas o que isso significa? O que significaria afirma que vivemos em uma cultura visual?

De acordo com o autor, enquanto para compreender o século dezenove seria preciso discutir as manifestações verbais, no jornal e no romance, a cultura pós-moderna seria melhor imaginada e compreendida visualmente. Em outras palavras, assim como seria impossível entender o século dezenove ignorando o papel dos jornais e dos romances na vida da sociedade, hoje, seria impossível compreender a sociedade em que vivemos sem uma atenção às novas formas de visualização e visibilidade. Isso ocorre porque vivemos numa sociedade na qual as práticas de produção, circulação e recepção de significado são eminentemente relacionadas às experiências visuais. A preocupação de Mirzoeff (idem) 
está orientada para a compreensão deste contexto específico em que desenvolvemos um tipo de sociabilidade amplamente centrada no sentido da visão e dependente dele. Para Mirzoeff, o campo da Cultura Visual (ou estudos visuais) dedica-se àquilo que faz de nossa cultura ser caracterizada como visual.

Para tentar compreender o argumento de Mirzoeff imagine a sociedade em que você vive hoje e a compare com a de seu tataravô. Em seguida pergunte-se: o que aconteceria se em ambas todas as pessoas subitamente ficassem cegos? Em qual das duas sociedades 0 trauma seria maior?

Segundo Mirzoeff, a Cultura Visual estaria preocupada com "os eventos visuais nos quais informação, significado ou prazer são solicitados pelos consumidores em interface com tecnologias visuais" (p. 3). Ele explica que o termo 'tecnologias visuais' se refere a "qualquer forma de aparato feito seja para ser olhado ou para amplificar a visão natural, das pinturas a óleo à televisão e a internet" ${ }^{8}$. Isso explica porque encontramos pesquisadores da Cultura Visual estudam fotografia analógica, cinema, televisão (desde a cobertura ao vivo de guerras ao redor do mundo, até novelas e reality shows ), internet (fotografias digitais ${ }^{9}$ e vídeos digitais que incluem desde o Google Streetview ${ }^{10}$, o Youtube e sites em que se pode ver ao vivo pessoas fazendo sexo diante de webcams), imagens de satélite (Google Earth e rastreamento militar), videogames ${ }^{11}$ (como o Second Life ou o World of Warcraft), raio-x e ultrassom com simulações 3D (que possibilitam avanços a medicina), vitrines, câmeras de vigilância e designs de ambientes que marcam as metrópoles contemporâneas.

É evidente que a experiência visual da qual Mirzoeff (1999) fala é bastante relacionada à experiência mediada por imagens tecnológicas cujo papel hoje não é apenas ampliar as possibilidades de difusão, mas, também, democratizar os meios de produção, expandindo o seguimento da população capaz de produzir imagens. Entretanto, deve ficar claro que não se trata de estudar imagens por si só. Afinal, a produção de imagens existe desde épocas remotas ${ }^{12}$. Para Mirzoeff, a cultura pós-moderna é visual não por causa das imagens

\footnotetext{
${ }^{8}$ Para Mirzoeff, o conceito de tecnologia inclui até mesmo pinturas a óleo, não se resume, portanto, ao que no senso comum se costuma chamar de tecnologia, como TVs ou celulares. Não se exclui aqui nenhuma das tecnologias, portanto, tradicionalmente associadas às Artes Visuais.

${ }^{9}$ A instalação Photography In Abundance (2011) do artista alemão Erik Kessels inspirou-se na quantidade de fotos que postamos na internet diariamente. A instalação foi feita com mais de 1 milhão de fotografias postadas em um único dia no site Flickr.

${ }^{10} \mathrm{O}$ projeto 9 eyes do artista Jon Rafman (http://9-eyes.com/) trabalha com imagens do StreetView.

11 Utilizando como inspiração os jogos eletrônicos de guerra, o artista iraquiano Wafaa Bilal (http://wafaabilal.com/) criou duas obras bastante interessantes, a instalação Domestic Tension (2007) e o jogo Virtual Jihadi (2008).

12 Estima-se que apesar do Homo Sapiens ter surgido por volta de 150 mil anos atrás, os traços mais antigos de imagens produzidas datam de apenas 30 mil anos. Sobre o surgimento das imagens sugiro assistir ao episódio The day pictures were born do documentário da BBC How Art Made the World.
} 
em si, mas, devido "à tendência moderna de figurar ou visualizar a existência". Esta tendência caracterizaria o período contemporâneo de maneira radicalmente diferente dos antecedentes e atingiria seu ápice hoje. Figurar ou visualizar a existência seria algo que sentimos como compulsório na pós-modernidade. Nós, indivíduos da contemporaneidade capitalista, globalizada e tecnológica, teríamos assim uma capacidade de processar informação visual impar na história da humanidade. Ainda segundo Mirzoeff, "esta notável capacidade de absorver e interpretar informação visual é a base da sociedade industrial e está se tornando ainda mais importante na era da informação. Ela não é um atributo natural do ser humano, mas, uma habilidade aprendida relativamente nova" (p.5). A proliferação de imagens seria uma das consequências desta sociabilidade baseada no sentido da visão. O desenvolvimento tecnológico acompanha este desejo de visualizar ${ }^{13}$. As tecnologias são cada vez mais visuais como uma consequência dessa tendência de figurar e visualizar a existência.

Há uma estreita relação entre o que fala Mirzoeff e as afirmações de Susan Sontag (2004) no seu livro de 1977, Sobre a fotografia. A autora comentava que estaríamos viciados em realçar a experiência visual e que faríamos isso por meio das máquinas fotográficas. A afirmação de Sontag se confirmou e, nesse sentido, "ter uma experiência se torna idêntico a tirar dela uma foto, e participar de um evento público tende, cada vez mais, a equivaler a olhar para ele, em forma fotografada" (2004, p.34).

A ideia de uma hegemonia do olhar, ou seja, da importância do olhar nas práticas culturais contemporâneas, no nosso modo de socialização, tem uma história de reflexões que antecede o campo de estudos da Cultura Visual. Por isso temos textos de autores como Sigmund Freud, Michael Foucault, Guy Debord, Jean Baudrillard nos principais readers do campo. Apenas a título de exemplo, segundo Foucault (1987), após o século 19, corpos e subjetividades passaram a ser domesticados (o que ele chama de Biopoder) a partir de estratégias de vigilância. Debord (1997), por sua vez, descrevia nossa sociedade como uma sociedade do espetáculo. Alertava para o fato de que o capitalismo nos controlava não simplesmente nos vigiando, como diria Foucault, mas regulando o que e como vemos. Esta seria uma sociedade do espetáculo porque somos espectadores de um espetáculo criado pela classe dominante para nos manter em um mundo de sonhos, separados uns dos outros ${ }^{14}$.

\footnotetext{
${ }^{13}$ Mirzoeff cita como exemplo deste fenômeno o caso dos computadores que tem esta interface primordialmente visual hoje, em oposição à interface baseada em texto com a qual surgiu, como consequência de sermos tão dependentes da visão.

${ }^{14}$ Jonathan Crary (2012) comenta a posição de Foucault contrária à teoria da sociedade do Espetáculo. Crary argumenta que espetáculo e vigilância não se opõem, como dá a entender Foucault. Ele diz: "Usando o panóptico de Benthan como objeto teórico fundamental, Foucault ressalta incessantemente as maneiras pelas quais os sujeitos humanos se tornaram objetos de observação, sob a forma de controle institucional ou do estudo científico e comportamental. Contudo, ele negligencia os novos modos pelos quais a própria visão se converte em um tipo
} 


\section{Um campo e/ou um objeto de estudo}

Então, como então podemos responder à pergunta "Qual é o objeto de estudo da Cultura Visual?" que dá início a este texto. A expressão "Cultura Visual" provoca expectativas que podem ajudar ou não a compreender este campo.

Uma dificuldade para tentar explicar e entender a expressão "cultura visual" está ligada ao fato de os alunos confundirem quando estamos falando do campo de estudo e do objeto de estudo. W.J.T. Mitchell (2002) já discutiu esta questão. Em princípio, segundo ele, o campo de estudos chamar-se-ia Estudos Visuais, enquanto o objeto de estudo deste campo seria a Cultura Visual. Entretanto, Mitchell deixa clara a sua opção por utilizar a expressão Cultura Visual para falar das duas coisas, do campo e do objeto. A seu ver, a palavra cultura encontra importância tão grande para a compreensão do campo que a expressão Estudos Visuais tornar-se-ia asséptica. O fato é que o termo Cultura Visual é hoje tão difundido para representar tanto campo quanto objeto que haveria mais prejuízos do que vantagens em alterá-lo.

Mas, por vezes temos dificuldade de identificar se falam de um campo ou de um objeto. É o caso de Mirzoeff (1999), pois de fato, assume como objeto de estudo uma cultura que a seu ver é visual. Este não é o caso de outros autores, como Mitchell, por exemplo, que não acredita que possamos falar em uma hegemonia da visão. Mitchell (2002) qualifica como uma falácia a noção de "uma dominação de mídias visuais e do espetáculo sobre as atividades do discurso verbal, da escrita, da textualidade e da leitura" (p.172). Ou seja, para Mitchell, trabalhar com a expressão Cultura Visual não indica que esteja qualificando alguma cultura como mais visual do que tátil, ou mais visual do que auditiva, ou mais visual do que verbal - assim como faz Mirzoeff. Mitchell faz parte de um grupo de autores que, segundo Paulo Knauss (2006), "considera que a cultura visual serve para pensar diferentes experiências visuais ao longo da história em diversos tempos e sociedades" (p.110)

Mas, de toda forma, Mitchell (2002) não se contrapõe totalmente à posição Mirzoeff. Isso fica evidente quando Mitchell deixa claro que a Cultura Visual teria como objetos de análise tanto a construção social da visão quanto a construção visual do social. Ele explica que a preocupação da Cultura Visual "não é somente o fato de nós vermos do modo que vemos, por sermos animais sociais, mas também o de nossos arranjos sociais tomarem a forma que têm, por sermos animais que veem" (p.171). Ou seja, como Mirzoeff, Mitchell

de disciplina ou forma de trabalho. Os aparelhos ópticos do século XIX envolveram, não menos que o panóptico, ordenamentos dos corpos no espaço, regulações das atividades e usos dos corpos individuais, que codificaram e normatizaram o observador no interior de sistemas rigidamente definidos em termos de consumo visual. Tratase de técnicas para administrar a atenção, para impor uma homogeneidade perceptiva com procedimentos que fizaram e isolaram o observador usando "partição e celularidade (...) nas quais o indivíduo é reduzido como força política". A organização da cultura de massa não se dirigiu pra alguma outra área não essencial ou superestrutural da prática social; ela estava plenamente inserida nas mesmas transformações que Foucault descreve" (p.26-27). 
preocupa-se com a ideia de que nossos arranjos sociais são influenciados pelo fato de possuirmos o sentido da visão, o que os diferencia é que ao contrário do primeiro, o segundo não acredita que o sentido da visão seja hoje claramente mais importante do que os outros.

\section{O ponto de vista da recepção}

Feita esta ressalva, podemos então discutir um segundo ponto sobre a proposta de Mirzoeff. Como vimos, Mirzoeff defende que a Cultura Visual estudaria especialmente o ponto de vista do consumidor, não do produtor.

Quanto a este ponto é importante observarmos que, embora os Estudos de Cultura Visual possam ser divididos em duas tendências, uma americana com Mitchell e Elkins como principais protagonistas, e outra inglesa, mais próxima dos estudos culturais e tendo Mirzoeff como representante, em ambas "a recepção dos artefatos visuais é uma característica essencial" (PREGORARO, 2011, p.10). Mas se de fato os Estudos de Cultura Visual tendem a privilegiar o receptor, então, por que isso acontece?

Para discutirmos mais profundamente esta questão é necessário relembrarmos o conceito de cultura como prática ou processo de produção, circulação e consumo de significado na vida social (CANCLINI, 2005, p.41). Cultura passou a ser definida assim na medida em que se propôs que o significado das coisas, eventos ou pessoas não é inerente a essas coisas, eventos ou pessoas. Assume-se, então, que significado é algo construído, sempre contingente, sempre mutante, e, portanto, para estudá-lo é preciso pensar contextos históricos específicos. Esta não tem sido a linha teórica teórica privilegiada pelas disciplinas que tradicionalmente estudam as imagens, por exemplo, pois acreditavam, ao contrário, que o significado era algo que estava incrustrado nas características objetivas da própria imagem ou era vinculado à intenção do seu produtor.

Por esta razão, os Estudos de Cultura Visual comprometem-se em analisar momentos de consumo/recepção/interpretação ${ }^{15}$ demonstrando que o significado dado a um mesmo objeto/fenômeno pode transformar-se através de usos e reapropriações. Exemplos de recepções diversas que subvertem e/ou ignoram a intenção dos criadores estão por todo lado. Enquanto escrevo este texto, por exemplo, centenas de internautas comentam e compartilham no Facebook o seguinte o anúncio da loja de acessórios femininos Couro Fino (Figura 4). Para uns, uma imagem inocente de uma criança brincando com as roupas de sua mãe, para outros uma horrenda erotização da infância.

\footnotetext{
${ }^{15}$ Seria importante questionar até que ponto os conceitos de interpretador, receptor e consumidor são ou não intercambiáveis. Imagino que não, no entanto, este debate ficará para um outro trabalho. Por enquanto, assumo as consequências de tratá-los como conectados.
} 


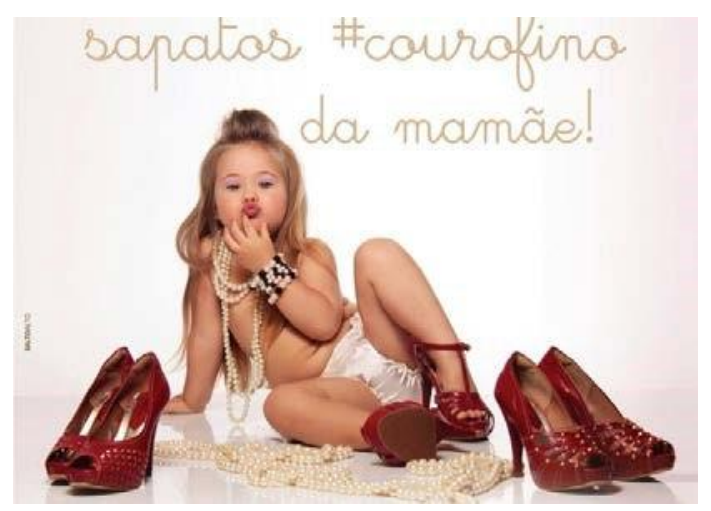

Figura 4 - Anúncio da loja Couro Fino

Destaco ainda o caso descrito no site Esferapública por Lucas Ospina (2013) sobre a recepção da escultura de Léon Ferrari La civilización occidental y cristiana (figura 5).

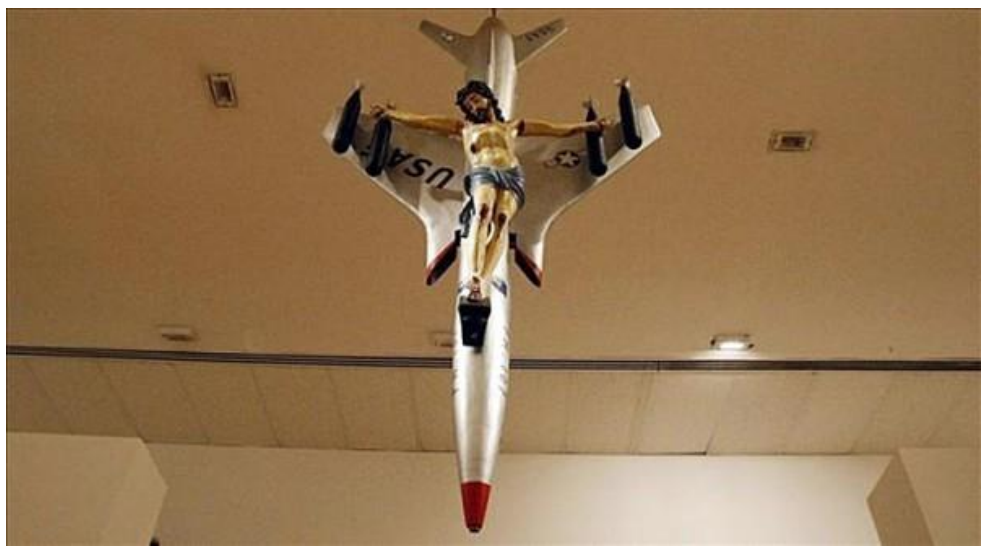

Figura 5 - La civilización occidental y cristiana. Léon Ferrari, $1966 .{ }^{16}$

Ospina apresenta o embate em Buenos Aires entre a comunidade católica liderada pelo hoje Papa Francisco e a comunidade laica a respeito do pedido de fechamento da exposição de Ferrari feito pessoalmente pelo então padre Jorge Bergoglio (era ano 2004). Na porta do museu os primeiros rezavam "Santa María madre de Dios...", enquanto os outros cantavam ironicamente "Iglesia Católica Go Home!". Segundo o artigo, Bergoglio descrevia a obra como "uma blasfêmia que envergonha nossa cidade", uma "zumbaria contra as pessoas de nosso Senhor Jesus Cristo e da Santíssima Virgem Maria". O ponto alto do artigo, no entanto, não seria nem a interpretação de Bergoglio, nem mesmo a de Ferrari, mas o texto do ofício do juiz Horacio Corti, que autorizou a reabertura da exposição. O juiz escreve o seguinte:

Ali quando um avião cruelmente ataca à vida humana, ali está Jesus sofrendo uma crucificação. Esta leitura, solicitada pela própria obra mostra algo talvez paradoxal, mas a que uma reflexão relaxada pode vir a

\footnotetext{
${ }^{16}$ A foto foi encontrada no próprio artigo de Ospina. Não há indicação sobre o nome do fotógrafo.
} 
considerar óbvia: a escultura "civilização ocidental e cristã" poderia ser vista como a expressão dos valores cristãos da paz, da compaixão para com os outros, de amor e rejeição da violência e crueldade. Seria a uma crítica cristã da sociedade, que geralmente se chama de cristã, mas, talvez, nessa visão, é menos do que pretendia. (...) Quero dizer, o trabalho de Ferrari pode ser uma testemunha do sofrimento humano (e do sofrimento de Deus que se tornou homem). (...) Logo, a ambiguidade do trabalho de Ferrari também é possível devido à riqueza do próprio Cristianismo, cuja história e ensinamento não podem ser reduzidos para uma visão monolítica, uniforme e única. Embora nos textos do artista (alguns deles listados no catálogo da amostra) o cristianismo seja certamente monolítico, são suas obras o que dizem o contrário, ao apontar a matriz que seu discurso não incorpora. De outro ângulo, podese dizer que se a obra de Ferrari pretende acusar a história da Igreja a partir da perspectiva dos direitos humanos, esses direitos estão enraizados, pelo menos em parte, à tradição intelectual e cultural do cristianismo em si.

Como se vê nas palavras do juiz, há sempre a possibilidade de novas interpretações. Aqui uma obra antes feita para questionar o cristianismo, passa a ter a exposição justificada por que conteria uma mensagem cristã. Para a Cultura Visual, toda experiência visual (não importa se concebida como arte ou não-arte) deve ser estudada considerando a história de sua recepção.

É claro que esta não é uma proposta nova. Já na década de 70, John Berger (1999) perguntava-se: "a quem pertence efetivamente o significado da arte do passado? Àqueles que o podem aplicar na sua vida, ou a uma hierarquia cultural de especialistas de relíquias?" (p. 36). A essa questão ele respondia assim: "a arte do passado já não existe mais como existiu outrora. A sua autoridade perdeu-se. Surgiu em seu lugar uma linguagem de imagens. O que importa agora é saber quem usa essa linguagem e com que fim" (p. 37). Esse recado faz hoje ainda mais sentido se considerarmos o quanto o desenvolvimento tecnológico facilitou para uma grande parcela da população a produção - e a pós-produção no sentido que Nicolas Bourriaud (2004) dá ao termo - e a difusão de imagens.

Acredito que abordar tais reapropriações é fundamental para compreendermos as experiências visuais. Do contrário, se optarmos por afirmar um único significado como sendo legítimo, nos comprometeremos com o estabelecimento de hierarquias e omitiremos uma história viva que inclui, mas, principalmente, vai muito além da intensão pontual de seus criadores. Cabe considerar tais intensões como mais uma de várias interpretações.

\section{Conclusão: Tentando mapear um labirinto}

Uma conclusão certa é que a expressão "cultura visual" pode ser um enigma para o aluno que tenta compreender sua multiplicidade de usos. Como professor da disciplina Estudos em Cultural Visual pude reviver as dúvidas que tive quando iniciava meus diálogos com este enigma. Hoje, no entanto, sinto que com um esforço de síntese, é possível organizar os caminhos percorridos pelos alunos em dois grupos. 
O primeiro, aquele que traduz a expressão Cultura Visual como uma cultura que é visual. Compreendem que estamos falando de algo que tem como foco a dimensão visual de uma cultura, mas não qualquer cultura, uma cultura específica, uma cultura visual. Mesmo sem essa clareza, se aproximam do caminho trilhado por Nicolas Mirzoeff. Daí surgem as perguntas: A nossa cultura é visual? Porque? Qual o papel das tecnologias nessa cultura visual? Qual o papel das imagens nessa cultura visual? O que seria uma cultura que não é visual? O que seria uma cultura auditiva, tátil ou olfativa? O que seria uma cultura oral ou verbal? E se fossemos cegos, se fossemos animais sem olhos, o que aconteceria com a nossa sociedade?

O segundo grupo, apega-se aos debates sobre os conceitos de visão e visualidade e assim seguem um caminho um pouco diferente. Assumem que estamos focando algo como visão cultural. Compreendem que falamos de algo que se preocupa com a dimensão cultural da visão, ou seja, com a dimensão cultural da experiência visual. Daí surgem perguntas como: Se não tivéssemos cultura, o que seria de nossa visão? Qual a dimensão não cultural da visão? O que é biológico, instintivo ou programado na visão e o que é aprendido ao longo de nossa vida social?

Desta forma passei a entender que para amenizar a angústia dos alunos é importante compreender que suas dúvidas associam-se a pelo menos dois caminhos possíveis. Ao explicar que as suas dúvidas podem ser organizadas e discutidas a partir destes caminhos, os ajuda a considerar que esses são os focos destacados por Mitchell (2002), ou seja, a construção visual do social e a construção social da visão. Portanto, para compreenderem em mais profundidade as preocupações do campo, é necessário transitar entre eles, sem negar um ou outro.

Ao final deste texto espero que você leitor perceba que existem vários caminhos/respostas para a questão "o que estuda a cultura visual?". Caminhos que se relacionam, mas, que não coincidem. Não omiti minhas opiniões e escolhas, mas, compreendo que podem não ser as suas. Escolha seu caminho e, quando puder, me escreva comentando o seu itinerário.

\section{Referencias}

BERGER, John. Modos de ver. Rio de Janeiro: Rocco, 1999.

BOURRIAUD, Nicolas. Pós-produção: como a arte reprograma o mundo contemporâneo. São Paulo: Martins Fontes, 2004.

CAMPOS, Ricardo Marnoto de Oliveira. Pintando a cidade: uma abordagem antropológica ao graffiti urbano. Tese (Doutorado em antropologia) - Universidade Aberta. Lisboa, 2007.

CANCLINI, Nestor Garcia. Diferentes, desiguais e desconectado: mapas da interculturalidades. Rio de Janeiro: Editora UFRJ, 2005. 
CHABRIS, Christopher; SIMONS, Daniel. O gorila invisível: e outros equívocos da intuição. Rio de Janeiro: Rocco, 2011.

COSTA, Fernando Braga da. Homens invisíveis: relato de uma humilhação social. São Paulo: Globo Livros, 2004

CRARY, Jonathan. Técnicas do observador: visão e modernidade no século XIX. Rio de Janeiro: Contraponto, 2012.

DEBORD, Guy. A sociedade do espetáculo: comentários sobre a sociedade do espetáculo. Rio de Janeiro: Contraponto, 1997.

ELKINS, James. Visual studies: a skeptical introduction. London: Routledge, 2003.

EVANS, Jessica; HALL, Stuart (org.). Visual Culture: the reader. London: Sage, 1999.

FOSTER, Hal (org.). Vision and visuality. Seattle: Bay Press, 1988.

FOUCAULT, Michel. Vigiar e punir. O nascimento da prisão. 32. ed. Petrópolis: Vozes, 1987.

HALL, Stuart. Da diáspora: identidades e mediações culturais. Belo Horizonte: Editora UFMG, 2003.

. The work of representation. In: Hall, Stuart (org.). Representation: cultural representation and signifying practices. London: Sage, 1997. p. 13-72.

JAY, Martin. Downcast eyes: the denigration of vision in twentieth-century french thought. London: University of California Press, 1994. Refractions of Violence. London: Routledge, 2003.

. That Visual turn: the advent of visual culture. Journal of Visual Culture. Vol.1. no.2, p.87-92. 2002.

KELLNER, Douglas. A cultura da mídia. Estudos Culturais: Identidade e política entre o moderno e o pós-modernos. Bauru, SP: EDUSC, 2001.

KNAUSS, Paulo. Aproximações disciplinares: história, arte e imagem. Anos 90, Porto Alegre, v.15, n.28, p.151-168, dez. 2008.

. O desafio de fazer história com imagens: arte e cultura visual. ArtCultura, Uberlândia, v. 8, n. 12, p. 97-115, jan.-jun. 2006.

LAMEIRA, A. P.; Gawryszewski,L. G.; Pereira Junior, A.. Neurônios Espelho. Psicologia USP, v. 17, p. 123-133, 2006.

MENESES, Ulpiano T. Bezerra. Rumo a uma história visual. In: Martins, José de Souza; Eckert, Cornelia; Caiuby Novaes, Sylvia (Org.). O imaginário e o poético nas Ciências Sociais. Bauru: Edusc, 2005.

MIRZOEFF, Nicholas. An introduction to visual culturee. London: Routledge, 1999.

. On Visuality. Journal of Visual Culture. v.5, n.1, 2006, p. 53-79.

Seinfeld. London: British Film Institute, 2008.

MITCHELL, W.J.T. Cloning Terror: The War of Images, 9/11 to the Present. Chicago: University Of Chicago Press, 2011.

. Showing seeing: a critique of visual culture. Journal of Visual Culture. vol. 1, no. 2, 2002. p. 165.181 .

OSPINA, Lucas. El día que el arte desnudó a Jorge Bergoglio. 2013. disponível em: <http://esferapublica.org/nfblog/?p=58684>. Acesso em: 16 mar. 2013.

PEGORARO, Éverly. Estudos da cultura visual e estudos culturais: aproximações e divergências. Confederación Iberoamericana de Asociaciones Científicas y Académicas de la comunicación. Anais. São Paulo, ECA-USP, 2011. 
SONTAG, Susan. Sobre fotografia. São Paulo: Companhia das Letras, 2004.

STURKEN, Marita. Tangled Memories: The Vietnam War, the AIDS Epidemic, and the Politics of Remembering. Los Angeles: University of California Press, 1997.

STURKEN, Marita; CARTWRIGHT, Lisa. Practices of looking: an introduction to visual culture. New York: Orford University Press, 2001.

WALKER, John A; CHAPLIN, Sarah. Una introducción a la cultura visual. Barcelona: Octaedro, 2002.

WOLFF, Janet. After Cultural Theory: The Power of Images, the Lure of Immediacy Journal of Visual Culture. vol. 11, no. 1, 2012. p. 3-19.

Pablo Sérvio

Recebido em: 25/07/2014

Aprovado em: 08/08/2014 